\title{
Luaran Klinis dan Analisis Biaya Konversi dari Antibiotik Intravena ke Oral pada Pasien Community Acquired Pneumonia di Rumah Sakit Akademik Universitas Gadjah Mada
}

\author{
Clinical Outcome and Cost Analysis of Conversion from Intravena to Oral Antibiotics in Community \\ Acquired Pneumonia Patients in Rumah Sakit Akademik Universitas Gadjah Mada \\ Altaufik Ngani' ${ }^{1}$, Titik Nuryastuti2 ${ }^{*}$, Tri Murti Andayani ${ }^{3}$ \\ ${ }^{1}$ Magister Farmasi Klinik, Fakultas Farmasi, Universitas Gadjah Mada \\ ${ }^{2}$ Fakultas Kedokteran, Kesehatan Masyarakat, dan Keperawatan, Universitas Gadjah Mada \\ ${ }^{3}$ Fakultas Farmasi, Universitas Gadjah Mada \\ Corresponding author: Titik Nuryastuti; Email: t.nuryastuti@ugm.ac.id \\ Submitted: 18-10-2020 Revised:26-12-2020 Accepted:05-01-2021
}

\begin{abstract}
ABSTRAK
Beberapa studi mengusulkan konversi terapi antibiotik intravena ke oral untuk menurunkan lama rawat inap dan biaya dalam pengobatan Community Acquired Pneumonia (CAP) yang masih menjadi masalah di Indonesia. Penelitian ini bertujuan untuk mengetahui gambaran tentang praktik konversi antibiotik intravena ke oral pada pasien CAP serta menganalisis biaya dari terapi tersebut. Penelitian ini dilakukan dengan rancangan cross sectional terhadap pasien CAP di RSA UGM. Data yang diambil berupa rekam medik pasien rawat inap periode Januari 2017-Desember 2019 yang selanjutnya dibagi ke dalam dua kelompok yakni kelompok konversi $\leq$ hari ke-3 dan kelompok konversi > hari ke-3. Hasil penelitian menunjukan bahwa switch therapy merupakan jenis konversi paling banyak digunakan (60,6\%). Merujuk pada luaran klinis, terdapat perbedaan yang signifikan $(\mathrm{p}<0,05)$ antara kelompok antibiotik intravena konversi $\leq$ hari ke-3 dan kelompok antibiotik antibiotik intravena konversi > hari ke 3 terhadap LOS $(4,21 \pm 0,99$ vs 5,65 $\pm 1,40)$. Hal yang sama terjadi pada analisis biaya, yang juga menunjukan perbedaan siginifikan $(\mathrm{p}<0,05)$ antara kelompok antibiotik intravena konversi $\leq$ hari ke-3 dan kelompok antibiotik intravena konversi >hari ke-3 terhadap biaya antibiotik dengan biaya total masing-masing Rp.126.022,33 vs Rp.274.283,82 dan Rp.2.610.283,66 vs Rp.3.696.681,06. Konversi antibiotik intravena ke oral $\leq$ hari ke-3 menghasilkan lama rawat inap yang lebih rendah dan penghematan biaya pengobatan.
\end{abstract}

Kata kunci: Biaya, CAP, intravena ke oral, konversi antibiotik.

\begin{abstract}
Several studies propose conversion of intravenous antibiotic to oral therapy could reduce the length of stay and costs of the treatment of Community Acquired Pneumonia (CAP) which is still a problem in Indonesia. This study aims to describe the practice of converting intravenous to oral antibiotics in CAP patients and to analyze the cost of this therapy. The study was a cross-sectional analytic study design of CAP patients at Academic Hospital of UGM. The medical records of CAP patients for the period January 2017-December 2019 were taken and further divided into two groups namely the conversion group $\leq 3$ rd day and the conversion group > 3rd day. The results showed that switch therapy was the most widely used type of conversion (60.6\%). Referring to clinical outcomes, there was a significant difference $(\mathrm{p}<0.05)$ between the $\leq 3^{\text {rd }}$ day antibiotik intravenous conversion antibiotic group and the $>3^{\text {rd }}$ intravenous antibiotic conversion group with LOS $(4,21 \pm 0,99$ vs $5,65 \pm 1,40)$. The similar was found in cost analysis, which also showed a significant difference $(\mathrm{p}<0.05)$ between the $\leq 3^{\text {rd }}$ antibiotik intravenous conversion group and the $>3^{\text {rd }}$ intravenous antibiotic conversion group to the cost of antibiotics with a total cost Rp.126.022,33 vs Rp.274.283,82 and Rp.2.610.283,66 vs Rp.3.696.681,06. Conversion of intravenous antibiotics to oral $\leq 3^{\text {rd }}$ day results in lower hospital stays and savings in medical costs
\end{abstract}

Keywords: antibiotic conversion, CAP, Cost, intravenous to oral

\section{PENDAHULUAN}

Community Acquired Pneumonia (CAP) merupakan suatu infeksi pada parenkim paruparu yang diperoleh dari luar rumah sakit atau fasilitas pelayanan kesehatan lanjutan pada pasien yang tidak mendapatkan pengobatan terkini dari system pelayanan kesehatan.
Diagnosis penyakit ini umumnya melalui gambaran klinis, pemeriksaan radiologis serta pemeriksaan fisik yang khas seperti hipoksemia (Alldredge dkk., 2013). Berdasarkan data yang dihimpun oleh PDPI tahun 2014, CAP menjadi salah satu penyebab kematian tertinggi didunia ketiga dari total 30 jenis penyakit mematikan. Di 
Indonesia, pneumonia termasuk dalam 10 besar penyakit rawat inap di rumah sakit dengan proporsi kasus 53,95 \% laki-laki dan 46,05\% perempuan, dengan Crude Fatality Rate (CFR) $7,6 \%$, atau yang tertinggi dibanding penyakit lain (PDPI, 2014). Tingginya angka insidensi ini tentu akan berpengaruh pada biaya perawatan pasien. Tercatat pada tahun 2005, Biaya perawatan untuk pasien dengan pneumonia pada tahun 2005 mencapai 40 miliar dolar, dengan biaya langsung 34 miliar dollar (Alldredge dkk., 2013). Maka konversi penggunaan terapi menjadi salah satu solusi untuk menekan tingginya biaya perawatan tersebut.

Beberapa studi telah mendemostrasikan, bahwa konversi terapi antibiotik intravena ke oral mampu menurunkan lama rawat inap dan biaya pengobatan (Antoni Castro-Guardiola, MD dkk., 2001; Cunha, 2001; Hendrickson dan North, 1995; Ramirez dkk., 1999, 1995). Penelitian Davis dkk (2005) menyimpulkan bahwa konversi antibiotik dengan metode sequential therapy dapat mengurangi biaya pengobatan sebesar $\$ 110 /$ pasien. Davis dkk melanjutkan bahwa, konversi tersebut tidak mengurangi efikasi dan lama perawatan pasien. Hal yang sama juga dilaporkan oleh Chandrasekhar dan Pokkavayalil (2019) bahwa strategi ini mampu minimalisasi $19.5 \%$ penggunan biaya antibiotik pasien tanpa adanya perubahan outcome terapi.

Namun, meskipun demikian, penelitian maupun bukti ilmiah terkait konvesi penggunaan antibiotik dalam terapi CAP diIndonesia masih sangat minim. Oleh karena itu, kami ingin mengevaluasi praktik konversi antibiotik intravena ke oral terkait dengan lama perawatan di rumah sakit dan penghematan biaya terapinya.

\section{METODOLOGI}

\section{Rancangan Penelitian}

Penelitian ini bersifat analitik cross sectional, dimulai dengan mengumpulkan data secara retrospektif. Teknik pengambilan sampel dalam penelitian ini dilakukan secara Concecutive sampling, yakni setiap populasi yang memenuhi kriteria inklusi yang telah ditetapkan akan dimasukan dalam penelitian. Data pasien dicatat dan dikumpulkan berdasarkan formulir yang telah disiapkan meliputi usia, berat badan, tinggi badan, jenis kelamin, jenis antibiotik, dan durasi pemberian antibiotik, penyakit penyerta. Data yang memenuhi kriteria inklusi dimasukkan dalam setiap kelompok yang sesuai yaitu kelompok konversi $\leq$ hari ke-3 dan kelompok konversi > hari ke-3 serta dilakukan matching berdasarkan usia, jenis kelamin, jaminan kesehatan, kelas perawatan dan penyakit penyerta non infeksi. Data pembiayaan pasien diambil dari catatan pembiayaan pasien dari bagian keuangan rumah sakit berupa biaya total pengobatan meliputi biaya akomodasi dan konsultasi, biaya pelayanan medis, biaya pemeriksaan laboratorium dan radiologi, biaya obat dan alat kesehatan, biaya antibiotik, dan biaya ruang perawatan.

Penelitian ini telah disetujui pelaksanaannya oleh Komite Etik Penelitian Komisi Etik Fakultas Kedokteran, Kesehatan Masyarakat dan Keperawatan Universitas Gadjah Mada, Yogyakarta dengan nomor KE/FK/1200/EC/2019.

\section{Subyek Penelitian}

Semua pasien yang terdiagnosa CAP selama periode penelitian yang memenuhi kriteria inklusi yaitu pasien dengan diagnosa CAP, konversi antibiotik intravena ke oral, pasien dewasa dengan usia $\geq 18$ tahun, dan rekam medik yang lengkap meliputi demografi pasien, diagnosa, tanda-tanda vital, catatan pengobatan. Pasien dengan kondisi imunocompromise, pasien dengan diagnosa infeksi lain, wanita hamil, pasien transfer dari ICU, pasien rujukan dari rumah sakit lain, dan pasien pulang paksa dieksklusi dari penelitian ini.

\section{Instrumen Penelitian}

Instrumen yang digunakan dalam penelitian ini berupa formulir pengambilan data rekam medik pasien CAP yang dirawat inap di Rumah Sakit Akademik UGM periode Januari 2017 - Desember 2019. Form tersebut berisi data demografi pasien, diagnosis, terapi yang diperoleh, hasil pemeriksaan laboratorium dan radiologi, hasil kultur bakteri, tanda-tanda vital, waktu konversi antibiotik intravena ke oral serta catatan pembayaran pasien.

\section{Analisis Data}

Analisis dekskriptif dilakukan untuk melihat angka kejadian CAP, demografi pasien meliputi: usia, jenis kelamin, ruang perawatan, tipe pembayaran perawatan penyakit penyerta 
Luaran Klinis dan Analisis Biaya Konversi dari Antibiotik Intravena ke Oral

Tabel I. Karakteristik Pasien Rawat Inap dengan CAP di RSA UGM

\begin{tabular}{lcc}
\hline Karakteristik & Jumlah (n) & Persentase (\%) \\
\hline Usia & & \\
18-60 & 41 & 41,4 \\
$>60$ & 58 & 58,6 \\
Jenis Kelamin & & \\
$\quad$ Laki-laki & 55 & 55,6 \\
$\quad$ Perempuan & 44 & 44,4 \\
Kelas Perawatan & & 27,3 \\
Kelas 1 & 27 & 17,2 \\
Kelas 2 & 17 & 55,6 \\
Kelas 3 & 55 & 90,9 \\
Jaminan Kesehatan & & 9,1 \\
BPJS & 90 & \\
Non-BPJS & 9 & 44,4 \\
Penyakit penyerta non infeksi (Chalrson Index) & & 41,4 \\
Skor 0 & 44 & 11,1 \\
Skor 1 & 41 & 3,1 \\
Skor 2 & 11 & \\
Skor 3 & 3 & \\
& & \\
\hline
\end{tabular}

non infeksi yang disajikan dalam bentuk persentase.

Sementara itu, perbedaan biaya dan lama perawatan/LOS antara kelompok konversi $\leq$ hari ke-3 dengan kelompok konversi > hari ke-3 dilakukan uji t. Uji normalitas pada penelitian ini menggunakan Kolmogorv-Smirnov dan dilanjutkan dengan uji Mann-Whitney. Hasil analisis disimpulkan dengan melihat nilai $p$ value dengan tingkat kepercayaan $95 \%$. Selisih biaya antara kelompok konversi $\leq$ hari ke-3 dengan kelompok konversi > hari ke-3 dinyatakan sebagai penghematan biaya.

\section{HASIL DAN PEMBAHASAN Karakteristik Pasien CAP}

Hasil penelitian menunjukan bahwa CAP lebih banyak terjadi laki laki dibanding perempuan yakni $55 \%$ vs $44 \%$. Berdasarkan usianya, data menunjukan bahwa pasien penyakit ini didominasi oleh geriatri berusia diatas $60(58,6 \%)$. Data populasi pasien dapat dilihat pada Tabel I. Data ini menggambarkan bahwa dengan bertambahnya usia meningkatkan risiko morbiditas terjadinya CAP.

Perubahan anatomi dan fisiologi pada pasien geriatri serta adanya penyakit komorbid turut berperan penting dalam meningkatkan frekuensi dan keparahan CAP (Rizqi dan Hasan, 2014). Pasien yang memiliki usia diatas 60 tahun juga lebih mudah terinfeksi pneumonia karena adanya gangguan refleks muntah, imunitas yang melemah, respons pengaturan suhu yang terganggu dan kelainan kardiopulmoner. Kelainan sistem saraf pusat dan refleks muntah juga turut berperan mengakibatkan pneumonia aspirasi. Kardiopulmoner yang mrngalami kelainan secara langsung berpengaruh terhadap penurunan fungsi jantung dan paru (Cunha, 2001). Sementara itu, tingginya angka kejadian penyakit ini pada pria diduga karena mobilitas yang tinggi serta pola hidup tidak sehat misalnya kebiasaan merokok dan mengonsumsi alkohol yang menjadi salah satu faktor resiko dari penyakit ini (Torres dkk., 2013). Semua pasien dirawat ruang perawatan non-ICU yang terdiri dari kelas 1 (27), Kelas 2 (17), Kelas 3 (55) yang menggunakan jaminan Badan Penyelenggara Jaminan sosial (BPJS) kesehatan lebih banyak daripada pasien yang tidak menggunakan BPJS 90 pasien $(90,9 \%)$ vs 9 pasien $(9,1 \%)$. Perjalanan penyakit pneumonia dapat dipengaruhi oleh penyakit penyerta dan dapat mengakibatkan kematian jika tidak ditangani dengan tepat. Penyakit penyerta yang diderita oleh pasien dapat dilihat pada tabel 2 . Data tersebut menunjukan bahwa penyakit paru obstruktif kronis dan diebetes melitus merupakan penyakit penyerta terbanyak masing-masing 19 pasien $(24,4 \%)$ dan 17 pasien $(21,8 \%)$. Keberadaan diabetes melitus 
Altaufik Ngani, et al

Tabel II. Penyakit Penyerta Non-Infeksi

\begin{tabular}{lcc}
\hline \multirow{2}{*}{ Penyakit Penyerta Non Infeksi } & \multicolumn{2}{c}{ Jumlah } \\
\cline { 2 - 3 } & $\mathbf{N}$ & $\mathbf{\%}$ \\
\hline PPOK & 19 & 24,4 \\
Diebetes melitus & 17 & 21,8 \\
Hipertensi & 12 & 15,4 \\
Dispepsia & 11 & 14,1 \\
CHF & 8 & 10,3 \\
AKI & 6 & 7,7 \\
CKD & 3 & 3,8 \\
Keganasan & 1 & 1,3 \\
CVA & 1 & 1,3 \\
\hline
\end{tabular}

Keterangan; CHF: Congesteive Heart failure; CKD: Chronic Kidney Disease; PPOK: Penyakit Paru Obstruktif Kronis; AKI: Acute Kidney Injury; CVA: Cerebrovascular Accident

Tabel III. Penggunaan Antibiotik Intravena pada pasien CAP

\begin{tabular}{llcc}
\hline & \multicolumn{1}{c}{ Antibiotik } & Jumlah & $\mathbf{\text { N }}$ \\
\cline { 3 - 4 } Tunggal & Levofloxacin & 21 & 21,3 \\
& Ceftriaxone & 18 & 18,3 \\
& Ceftazidim & 3 & 3 \\
& Meropenem & 2 & 2 \\
& Azitromicin & 1 & 1 \\
& Cefotaxime & 1 & 1 \\
& Ceftriaxone+Azitromicin & 38 & 38,4 \\
& Ceftriaxone+Levofloxacin & 1 & 1 \\
& Cefuroxime+Azitromicin & 3 & 3 \\
& Ceftazidim+Azitromicin & 3 & 3 \\
& Cefotaxime+Azitromicin & 2 & 2 \\
& Cefoperazon+Azitromicin & 1 & 1 \\
& Ceftazidim+Ciprofloxacin & 1 & 1 \\
Total & Ciprofloxacin+Azitromicin & 1 & 1 \\
& Cefoperazon-sulbactam+Azitromicin & 1 & 1 \\
& Levofloxacin+Azitromicin & 1 & 1 \\
& Cefuroxime+Levofloxacin & 1 & 100 \\
\hline
\end{tabular}

dan PPOK ini dapat meningkat risiko kejadian pneumonia (Mannino dkk., 2009; Torres dkk., 2013).

\section{Gambaran Konversi Antibiotik Intravena ke Oral}

Pemberian antibiotik pada pasien rawat inap di RSA UGM umunya dalam dibentuk tunggal maupun kombinasi. Adapun jenis antibiotik yang digunakan dapat dilihat pada tabel III. Levofloxacin merupakan yang paling banyak digunakan monoterapi $(21,3 \%)$, diikuti oleh ceftriaxone, ceftazidim, meropenem, azitromisin, dan cefotaxime. Semenntara itu, pada kombinasi antibiotik, kami menemukan bahwa ceftriaxone + azitromisin merupakan yang paling banyak diresepkan dirumah sakit tersebut. Penggunaan terapi kombinasi antibiotik ini umunya bertujuan untuk meningkatkan efektifitas antibiotik pada infeksi yang spesifik, serta untuk memperlambat dan mengurangi risiko adanya resistensi bakteri (Kuswandi, 2016). Ceftriaxone + azitromisin merupakan kombinasi dari golongan $\beta$-Laktam plus makrolida. Kombinasi dari kedua golongan tersebut telah lama dikaitkan dengan luaran 
Tabel IV. Jenis Konversi Antibitiotik pada Terapi CAP

\begin{tabular}{|c|c|c|c|c|}
\hline Jenis Konversi & $\mathbf{N}$ & $\%$ & Intravena & Oral \\
\hline & & & Ceftriaxone & Cefixime \\
\hline \multirow[t]{2}{*}{ Switch therapy } & 60 & 60,6 & Cefoperazone & Cefixime \\
\hline & & & Cefoperazone-Sulbactam & Cefixime \\
\hline Sequential therapy & 17 & 17,2 & Levofloxacin & Levofloxacin \\
\hline \multirow[t]{3}{*}{ Step down therapy } & 3 & 3,0 & Ciprofloxacin & Cefixime \\
\hline & & & Ceftriaxone & Levofloxacin \\
\hline & & & Levofloxacin & Cefixime \\
\hline \multirow[t]{3}{*}{ Tidak tepat } & 19 & 19,2 & Ceftazidim & Cefixime \\
\hline & & & Ceftriaxone & Azitromisin \\
\hline & & & Azitromisin & Doksisiklin \\
\hline Total & 99 & 100 & & \\
\hline
\end{tabular}

klinis yang lebih baik pada pasien CAP yang parah, mungkin karena efek imunomodulator makrolida (File, 2020).

\section{Konversi Antibiotik Intravena ke Oral}

Pasien CAP yang membutuhkan rawat inap umumnya dimulai dengan terapi anibiotik intravena dan beralih ke antibiotik oral ketika kondisi klinis membaik, stabil secara hemodinamik, mampu minum obat oral, dan saluran pencernaan berfungsi normal (File, 2020). Konversi antibiotik intravena ke oral harus memperhatikan ketersediaan antibiotik yang diberikan secara intravena dan antibiotik oral yang efektifitasnya mampu mengimbangi efektifitas antibiotik intravena yang telah digunakan (PDPI, 2014). Gambaran jenis konversi antibiotik intravena ke oral pada terapi CAP dalam penelitian dapat dilihat pada tabel IV.

Berdasarkan jenis konversi, Switch therapy merupakan metode konversi yang paling sering dipilih yakni sebanyak $60(60,6 \%)$. Antibiotik intavena yang digunakan pada jenis konversi ini merupakan golongan sefalosporin generasi III yang didominasi oleh ceftriaxone dan seluruhnya mengunakan antibiotik oral cefixime. Konversi sefalosporin intravena generasi III ke antibiotik oral cefixime menunjukkan respon klinis yang baik dan meminimalkan rawat inap dirumah sakit (Ramirez dkk., 1995). Selain metode tersebut, merupakan metode lain dipilih dalam konversi ini adalah Squential therapy sebanyak 17 $(17,2 \%)$ yang keseluruhannya adalah antibiotik bread spectrum yakni levofloxacin iv ke levofloxacin oral. Levofloxacin merupakan antibiotik yang efektif pada bakteri gram positif (Streptococcus pneumoniae dan Staphylococcus aureus) dan gram negatif (Escherichia coli, Moraxella catarrhalis, Haemophilus influenzae, Klebsiella pneumoniae dan Pseudomonas aeruginosa). Selain itu, antibiotik ini juga efektif terhadap patogen pneumonia atipikal seperti Chlamydia pneumoniae, Legionella pneumophila dan Mycoplasma pneumonia. Konversi levofloxacin iv ke levofloxacin ini telah terbukti dapat mengurangi lama perawatan dan biaya pengobatan pada pengobatan pasien rawat inap dengan CAP (Norrby dkk., 1998; Restrepo dan Frei, 2010). Step down therapy merupakan yang paling jarang digunakan (3\%) yakni ciprofloxacin intravena ke cefixime oral. Dalam penelitian ini, kami juga menemukan adanya konversi yang tidak tepat 19 (19,2\%) yakni ceftriaxone iv ke levofloxacin oral, levofloxacin iv ke cefixime oral, ceftazidim iv ke cefixime oral, ceftriaxone iv ke azitromisin, dan azitromisin iv ke doksisiklin.

\section{Analisis Luaran Klinis}

Terapi pasien rawat inap dengan CAP umumnya diawali dengan antibiotik intravena yang diberikan sesegera mungkin jika diagnosa sudah ditegakkan dan dilakukan evaluasi pada 48-72 jam pertama. Selanjutnya jika ditemukan perbaikan kondisi klinis, dapat dilakukan konversi ke antibiotik oral dengan switch therapy, sequential therapy atau step down therapy. Konversi antibiotik intravena ke oral dapat mempengaruhi luaran klinik dan biaya pengobatan. Untuk menggambarkan pengaruh tersebut, dilakukan pengelompokan berdasarkan durasi pemberian antibiotik intravena dan waktu konversi antibiotik intravena ke oral sehingga diperoleh kelompok antibiotik intravena konversi $\leq$ hari ke $3(n=33)$ 
Tabel V. Distribusi Karakteristik Pasien CAP

\begin{tabular}{|c|c|c|c|}
\hline \multirow[b]{2}{*}{ Karakteristik } & \multicolumn{2}{|c|}{ Kelompok } & \multirow[b]{2}{*}{$\mathbf{P}$} \\
\hline & $\begin{array}{c}\text { Antibiotik Intravena } \\
\text { Konversi } \leq \text { Hari ke } 3 \\
(n=33)\end{array}$ & $\begin{array}{c}\text { Antibiotik Intravena } \\
\text { Konversi >Hari ke } 3 \\
(n=66)\end{array}$ & \\
\hline Umur, mean \pm SD & $62,18 \pm 16,81$ & $62,74 \pm 16,49$ & $0,60^{\mathrm{a}}$ \\
\hline Jenis Kelamin, n (\%) & & & $0,43^{b}$ \\
\hline Laki-laki & $16(48,50)$ & $39(59,10)$ & \\
\hline Perempuan & $17(51,50)$ & $27(40,90)$ & \\
\hline Jaminan Kesehatan, n (\%) & & & $0,71^{\mathrm{c}}$ \\
\hline BPJS & $31(93,90)$ & $59(89,40)$ & \\
\hline Non BPJS & $2(6,10)$ & $7(10,60)$ & \\
\hline Kelas Perawatan, n (\%) & & & $0,62^{\mathrm{b}}$ \\
\hline Kelas 1 & $10(30,30)$ & $17(25,80)$ & \\
\hline Kelas 2 & $4(12,10)$ & $13(19,70)$ & \\
\hline Kelas 3 & $19(57,60)$ & $37(55,50)$ & \\
\hline $\begin{array}{l}\text { Charlson Comorbidity } \\
\text { index, Mean } \pm \text { SD }\end{array}$ & $0,85 \pm 0,79$ & $0,67 \pm 0,77$ & $0,23^{\mathrm{d}}$ \\
\hline
\end{tabular}

Keterangan: ${ }^{a}$ Indepentend $t$-test; ${ }^{b}$ Chi squere; ${ }^{c}$ Fisher's test; ${ }^{\mathrm{d}}$ Mann Whitney; Signifikansi $(\mathrm{P}<0,05)$

Tabel VI. Kondisi Klinis Pasien CAP

\begin{tabular}{lcc}
\hline \multirow{2}{*}{ Kelompok } & \multicolumn{2}{c}{ Kondisi klinis pada 48-72 jam (n=99) } \\
\cline { 2 - 3 } & Membaik & Belum Membaik \\
\hline Antibiotik Intravena Konversi $\leq$ Hari ke 3 $(\mathrm{n}=33)$ & 33 & 0 \\
Antibiotik Intravena Konversi $>$ Hari ke $3(\mathrm{n}=66)$ & 62 & 4 \\
\hline
\end{tabular}

dan kelompok antibiotik intravena konversi $>$ hari ke $3 \quad(n=66)$. Pengelompokan ini didasarkan bahwa sebanyak $2 / 3$ pasien mengalami perbaikan kondisi klinis dan memenuhi kriteria untuk beralih ke antibiotik oral pada 3 hari pertama (Mandell dkk., 2007). Sebanyak $40 \%$ pasien CAP yang memulai terapi dengan antibiotik intravena dapat dikonversi ke antibiotik oral setelah 2-3 hari terapi (Shirin, 2018).

Data dari dua kelompok tersebut dilakukan matching berdasarkan karakteristik pasien meliputi usia, jenis kelamin, jaminan kesehatan, kelas perawatan, dan penyakit penyerta (CCI Score). Distribusi usia, jenis kelamin, jaminan kesehatan, kelas perawatan dan keparahan komorbid antara dua kelompok tidak berbeda secara bermakana dilihat dari pvalue $>0,05$ (Tabel. 5).

Dalam penelitian ini, dilakukan perbandingan antara kelompok antibiotik intravena konversi $\leq$ hari ke 3 dan kelompok antibiotik antibiotik intravena konversi $>$ hari ke 3 terhadap luaran klinik dan biaya pengobatan pada pasien rawat inap non-ICU dengan CAP.
Luaran klinik yang menjadi fokus dalam penelitian ini yaitu lama perawatan/length of stay (LOS) yang dihitung sejak masuk sampai keluar rumah sakit dalam satu episode rawat inap dan dinyatakan dalam satuan hari.

Konversi antibiotik intravena ke oral dilakukan saat pasien mengalami perbaikan kondisi klinis. Perbaikan kondisi klinis meliputi suhu tubuh $\leq 37,8$, detak jantung $\leq 100$ kali/menit, laju pernapasan $\leq 24 \mathrm{kali} / \mathrm{menit}$, tekanan darah sistolik $\geq 90 \mathrm{mmHg}$, saturasi oksigen arteri $\geq 90 \%$ atau $\mathrm{PO} \neg 2 \geq 60 \%$, kemampuan mempertahankan asupan oral, dan status mental normal yang ditemukan saat 4872 jam setelah mendapat terapi antibiotik intravena. Kondisi klinis pasien pada penelitian ini setelah 48-72 mendapatkan terapi dapat dilihat pada tabel 6. Data pada tabel tersebut menginformasikan bahwa penggunaan konversi sebagai terapi lanjutan dapat memperbaiki kondisi klinis 33 pasien dari total 99 pasien yang menerima konversi antibiotik setelah 48-72 jam. Hal tersebut sejalan dengan yang direkomendasikan oleh IDSA/ATS (2007) dan PDPI (2014) bahwa terapi antibiotik intravena 
Tabel VII. Waktu Konversi terhadap Biaya dan LOS

\begin{tabular}{lccc}
\hline \multirow{2}{*}{ Konversi (n) } & LOS (Hari), & \multicolumn{2}{c}{ Biaya (Rp), Mean \pm SD } \\
\cline { 3 - 4 } & Mean \pm SD & Biaya Antibiotik & Biaya Total \\
\hline Hari ke 3 (33) & $4,21 \pm 0,99$ & $126.022,33 \pm 157.144,73$ & $2.610 .283,67 \pm 1.040105,78$ \\
Hari ke 4 (24) & $4,58 \pm 0,72$ & $160.538,67 \pm 130.027,99$ & $2.875 .820,63 \pm 834.971,91$ \\
Hari ke 5 (25) & $5,60 \pm 0,76$ & $326.617,20 \pm 353,928,49$ & $3.656 .692,60 \pm 1.505 .014,49$ \\
Hari ke 6 (6) & $7,00 \pm 0,63$ & $329.45417 \pm 376.363,33$ & $4.156 .276,50 \pm 986.907,14$ \\
Hari ke 7 (6) & $7,80 \pm 0,45$ & $500.702,80 \pm 455.742,37$ & $6.858 .991,40 \pm 1.457 .644,70$ \\
Hari ke 8 (1) & $9,00 \pm-$ & $178.300,00 \pm-$ & $4.324 .900 \pm-$ \\
Hari Ke 9 (1) & $10,00 \pm-$ & $328.700,00 \pm-$ & $5.199 .700 \pm-$ \\
\hline
\end{tabular}

Tabel VIII. Perbandingan Luaran klinik dan Biaya Pengobatan Pasien CAP

\begin{tabular}{lccc}
\hline Kelompok & \multicolumn{3}{c}{ Parameter } \\
\cline { 2 - 4 } & $\begin{array}{c}\text { LOS (Hari) } \\
\text { SD }\end{array}$ & $\begin{array}{c}\text { Biaya Antibiotik (Rp), } \\
\text { Mean } \pm \text { SD }\end{array}$ & $\begin{array}{c}\text { Biaya Total (Rp), } \\
\text { Mean } \pm \text { SD }\end{array}$ \\
\hline $\begin{array}{l}\text { Antibiotik Intravena } \\
\text { Konversi } \leq \text { Hari ke 3 } \\
\text { (n=33) }\end{array}$ & $4,21 \pm 0,99$ & $126.022,33 \pm 157.144,73$ & $2.610 .283,66 \pm 1.040 .105,78$ \\
Antibiotik Intravena & & & \\
$\begin{array}{l}\text { Konversi >Hari ke 3 } \\
\text { (n=62) }\end{array}$ & $5,65 \pm 1,40$ & $274.283,82 \pm 302.991,44$ & $3.696 .681,06 \pm 1.588 .375,66$ \\
Significant difference & 1,44 & $148.261,49$ & $1.086 .397,40$ \\
P-Value & $0,000^{*}$ & $0,000^{*}$ & $0,000^{*}$ \\
\hline
\end{tabular}

pada pasien rawat inap dengan CAP dapat dikonversi ke antibiotik oral setelah 48-72 jam saat pasien mengalami perbaikan kondisi klinis. Lebih lanjut, penelitian ini juga menemukan bahwa 62 pasien mengalami perbaikan kondisi klinis pada 48-72 jam, namun tidak dilakukan konversi ke antibiotik oral sebagai terapi lanjutan. Tidak adanya konversi ini tentu berdampak pada bertambahnya LOS pasien dirumah sakit dan meningkatnya biaya pengobatan. Sementara itu, hasil analisis perbandingan luaran klinis antara kelompok antibiotik intravena konversi $\leq$ hari ke 3 dan kelompok antibiotik antibiotik intravena konversi >hari ke 3 ditemukan adanya perbedaan yang signifikan pada LOS $(4,21 \pm 0,992$ vs $5,78 \pm 1,496)(p<0,05)$ (Tabel 8).

\section{Analisis Biaya Konversi Antibiotik Intravena ke Oral}

Analisis biaya yang dilakukan dalam penelitian ini berupa analisis biaya medik langsung berupa biaya total pengobatan yang terdiri atas akomodasi rawat inap, biaya tindakan dan jasa medis, biaya pemeriksaan penunjang diagnostik (biaya laboratorium dan foto thorax), biaya antibiotik, biaya obat dan alat kesehatan. (Tabel VII). Dari tabel tersebut dapat diketahui bahwa semakin cepat waktu konversi antibiotik intravena ke oral, maka akan menurunkan LOS pasien dirumah sakit.

Data tabel tersebut menampilkan gambaran waktu konversi antibiotik terhadap rata-rata biaya antibiotik maupun biaya total menunjukkan adanya peningkatan dari konversi hari ke 3 sampai konversi hari ke 7 namun mengalami penurunan pada konversi hari ke 8 dan konversi hari ke 9. Penurunan ini dapat disebabkan oleh pemilihan antibiotik intravena yang diberikan kepada pasien.

Sementara itu, hasil analisis perbedaan biaya dengan uji mann whitney pada tabel VIII, menunjukan perbedaan siginifikan antara kelompok antibiotik intravena konversi $\leq$ hari ke 3 dan kelompok antibiotik intravena konversi >hari ke 3 terhadap biaya antibiotik. Adapun biaya pengobatan masing-masing dari kelompok tersebut antara lain Rp. 126.022,33 vs Rp. $274.283,82$ dan Rp. 2.610.283,66 vs Rp. 3.696.681,06 $(\mathrm{p}<0,05)$. Dari hasil tersebut, diperoleh selisih biaya sebesar Rp. 148.261,49 untuk biaya antibiotik dan Rp. 1.086.397,40 untuk biaya total pengobatan. Selisih biaya tersebut mengindikasikan bahwa kelompok 
antibiotik intravena konversi $\leq$ hari ke 3 memberikan penghematan biaya antibiotik maupun biaya pengobatan.

\section{KESIMPULAN}

Switch therapy merupakan metode yang banyak diadopsi dalam konversi penggunaan antibiotik dalam pengobatan CAP di RSA UGM. Strategi Konversi antibiotik intravena ke oral $\leq$ hari ke 3 terbukti mampu memberikan lama rawat inap yang pendek dan penghematan biaya pengobatan penyakit ini.

\section{UCAPAN TERIMAKASIH}

Kami mengucapkan banyak terimakasih kepada RSA UGM, program studi Farmasi Klinik UGM serta pihak terkait yang telah membantu penyelesaian penelitian ini.

\section{DAFTAR PUSTAKA}

Alldredge, B.K., Affairs, A., Francisco, S., Francisco, S., Corelli, R.L., Francisco, S., dkk., 2013. Applied Therapeutics The Clinical Use of Drugs, Tenth Edit. Ed. Lippincott Williams \& Wilkins, A Wolters Kluwer.

Antoni Castro-Guardiola, MD, P., Alfonso-Luis Viejo-Rodriguez, M., S'ilvia Soler-Simon, M., Arola Armengou-Arxe', MD Vicenta Bisbe-Company, MD, Georgina Peñarroja-Matutano, M., dan Josep Bisbe-Company, MD, Ferran Garcl'aBragado, MD, P., 2001. Efficacy and Safety of Oral and Early-switch Therapy for Community-acquired Pneumonia : 9343:.

Chandrasekhar, D. dan Pokkavayalil, V., 2018. Cost minimization analysis on IV to oral conversion of antimicrobial agent by the clinical pharmacist intervention. Clinical Epidemiology and Global Health, 6-11.

Cunha, B.A., 2001. Oral or Intravenous-to-oral Antibiotic Switch Therapy for Treating Patients with Community- acquired Pneumonia 9343: .

Davis, S.L., Delgado, G., dan Mckinnon, P.S., 2005. Pharmacoeconomic Considerations Associated with the Use of Intravenousto-Oral Moxifloxacin for CommunityAcquired Pneumonia 63110.
File, T.., 2020. Treatment of CommunityAcquired Pneumonia in Adults who Require Hospitalization. UptoDate, 1-42.

Hendrickson, J.R. dan North, D.S., 1995. Pharmacoeconomic Benefit Of Antffiiotic Step-Down Therapy : Converting Patients From Intravenous Cefrriaxone To Oral Cefpodoxime Proxetil.29: 561-565.

Kuswandi, 2016. Resistensi Antibiotik. Grafika Indah, Yogyakarta, Indonesia.

Mandell, L.A., Wunderink, R.G., Anzueto, A., Bartlett, J.G., Campbell, G.D., Dean, N.C., dkk., 2007. Infectious Diseases Society of America / American Thoracic Society Consensus Guidelines on the Management of Community-Acquired Pneumonia in Adults 44: .

Norrby, S.R., Petermann, W., Willcox, P.A., Vetter, N., dan Salewski, E., 1998. A Comparative Study of Levofloxacin and Ceftriaxone in the Treatment of Hospitalized Patients with Pneumonia 397-404.

PDPI, 2014. Pneimonia Komunitas: Pedoman Diagnosis \& Penatalaksanaan Di Indonesia, Edisi II.

Ramirez, J.A., Srinath, L., Ahkee, S., dan Martin, J., 1995. Early Cephalosporins Hospitalized Community-Acquired.

Ramirez, J.A., Vargas, S., Ritter, G.W., Brier, M.E., Wright, A., Smith, S., dkk., 1999. Early Switch From Intravenous to Oral Antibiotics and Early Hospital Discharge 159: .

Restrepo, M.I. dan Frei, C.R., 2010. Health Economics of Use Fluoroquinolones to Treat Patients with Community-Acquired Pneumonia. AJM, 123: S39-S46.

Rizqi, M.H. dan Hasan, H., 2014. Tinjauan Imunologi Pneumonia pada Pasien Geriatri 41: 14-18.

Shirin, A., 2018. Intravenous-to-Oral Switch Therapy. available from url: https://emedicine.medscape.com/article /237521-overview

Torres, A., Peetermans, W.E., Viegi, G., dan Blasi, F., 2013. Risk factors for communityacquired pneumonia in adults in Europe : a literature review 1057-1065. 